\title{
Collaborative Educational Game for Thai Primary School Students
}

\author{
Natticha Gasonpan \\ School of Information Technology \\ Mae Fah Luang University, Chiang Rai, \\ Thailand.+6653916765 natticha_mick@mfu.ac.th
}

\author{
Punnarumol Temdee \\ School of Information Technology \\ Mae Fah Luang University,Chiang Rai, \\ Thailand.+6653916765 punnarumol@mfu.ac.th
}

\begin{abstract}
English language, Mathematics and Science for life are mandatory subjects for Thai students to finish their primary school studies. Regarding the unsatisfied result of the annual assessment, there are many students fail those subjects every year. This paper thus proposes the educational computer game to enhance learning of English language, Mathematics and Sciences subjects. The proposed game employs the concept of collaborative learning integrated into the game to promote the better understanding of contents and the familiarization of team work experience, while the players are still filled with the joy and the challenge. The proposed game is designed as a multi-players online game. All players compete among each other to be a leader and conduct the game along with help from team members to achieve the goal. The developed game is evaluated with 2 aspects including the learning efficiency and the satisfaction of students. The empirical study is conducted with 100 students from 3 different primary schools in Chiang Rai, Thailand. These students are divided into 2 groups including the group playing game individually and collaboratively respectively. The first group has 25 students while the second group has 15 groups with 5 students per each. The results reveal that, the students playing game collaboratively can achieve higher learning efficiency than the students playing game individually. Moreover, the collaborative game obtains Good satisfaction level by the students.
\end{abstract}

$$
\text { Keywords-Educational Games, }
$$

Edutainment,

Collaborative Learning, Collaborative Games

\section{INTRODUCTION}

At present, the teachers are not only responsible for transferring knowledge to their students in the classrooms but also creating learning media to motivate and encourage the learners to learn by themselves. Because the learners want to learn under the atmosphere of fun and joyfulness to gain knowledge for solving problems, the term "Edutainment" $[1,2]$ thus has been widely introduced recently. Edutainment integrates the concept of education and entertainment together with the advanced Information Communication Technology (ICT) and multimedia technology. The educators nowadays see benefits of Edutainment as the supplement to promote more effective learning [1,3]. Edutainment is derived from two reasons. Firstly, people usually have problems in learning difficult things, so it is necessary to add something that stimulates motivation and interest of learning and understanding [1]. Finally, due to the perspectives of the society that the social entertainments, such as cartoons, games and movies are joyful to people, so it is necessary to increase more knowledge in those social entertainments $[2,4]$. Therefore, the entertainment producers have intention for the learner to have more than just entertainment $[3,5]$ but also knowledge. Those reasons cause 2 types of edutainment. The first type requires learners to participate in the activities such as responding to or interacting with the media as the games. The second type does not require learners to participate, but only listening to or watching, for example, watching movies, visiting museums or zoo, etc. Generally edutainment is widely found in different forms of medias, such as computer games, Internet / website, digital television [6,7], etc. Because these activities are fun and they can create motivation in learning more than the traditional approach $[1,6,8]$, most elementary schools around the world offer the curriculums that is divided into subject matters which must be appropriate for student's level into different kinds of learning activities and medias. From the observation in the classroom, it has found that content in some lessons are difficult to explain to students. Especially the subjects that develop thinking skill are usually boring for students [1], Therefore the edutainment is now expected to take the main role for motivating the students to learn more effectively under the fun and joyfulness atmosphere.

Regarding a result from the assessment of standard quality in 2008 by the Bureau of Education Testing, Office of the Basic Education Commission, Ministry of Education, it is shown that the number of Thai primary school students having the age between 11-12 years old, who pass the good level $(3.44 \%)$ are much less than the students who pass the required improvement level $(33.62 \%)$ and the fair level $(62.94 \%)$. These results are from the total numbers of 197,910 grade six students testing English language, Mathematics and Science for Life [9]. This evidence implies that most of grade six Thai students now require the need to improve their learning efficiencies in those three subjects. For this reason, this paper proposes a concept of Edutainment to develop the game for grade six students to promote learning efficiency for those three subjects at the same time. The statistics from the National Statistical Office in 2002 indicated that three million Thai teenagers having the age between $11-14$ years old use computers for playing games as the most reason [10]. In addition, the research [11] has indicated that the number of game players increase more every year [12]. Because students love to play computer games and they are willing to spend more time with computer games, so implementing computer games as tools to develop students' learning is more appropriate strategy for this paper. 
Besides developing the game to convey the knowledge to the learners under the joyful atmosphere as the concept of Edutainment, this paper also implements the concept of collaborative learning into the developed computer game. Collaborative learning has been successfully introduced as the learning strategy to promote the better understanding of content to the learners through team work experience. The principle of collaborative learning is that all team members build the consensus by interacting among each others. Moreover, the students help among each other to achieve the common goal together. Because the traditional game is more competition, this paper thus presents the collaborative game to promote not only the joyful atmosphere but also the collaborative atmosphere where the learners can perceive the positive attitude of working in team.

This paper is organized as following. Section 2 shows the literature reviews of computer games and collaborative learning. Section 3 describes the proposed work. Section 4 shows the research methodology. Section 5 shows the empirical study and results. Section 6 is the conclusion of this paper.

\section{LITERATURE REVIEW}

\subsection{Computer Games}

Computer game normally is an implementation of lessons from subject matters with the graphic computer games. It can also be a simulation of a specific situation $[13,14]$. Currently traditional computer games for education can be played alone offline to promote the individual learning $[15,16]$. Once the computer games are developed as multi-player games, there is the need of the internet connection called online game [12]. Currently, online games are widely used for the primary school students for their self studies within or outside the classroom for solving the problems given by the teachers $[12,13]$. However, the multi-player online games are not widely used in education area. The general multiplayers online games are used for the purpose of entertainment only. The games are generally designed for the players to compete among each other to be a winner. This evidence may affect the negative behavior of the learners that they aim to overcome more than to help among each other. This paper thus would like to propose the online multi-player games for education game which is to promote the collaborative atmosphere instead of competitive atmosphere as mentioned before.

\subsection{Collaborative Learning}

Collaborative learning can reduce the risk of negative behaviors and help students to learn effectively [17]. At the same time, collaborative learning can also promote the learning environment where there is the share of knowledge and the acceptance of each others' options among students. The basic elements of collaborative learning are positive interdependences among students, primitive interactions of team members, personal responsibility, small group skills and group processing $[18,19]$. At present, the implementation of collaborative learning can be seen as 2 types. The first type is happened in the classroom where the teacher builds the learning activities for students to work together as a group $[18,20]$. The second type is happened through the network, where the students work with other members via the Internet such as e-learning, conference calls, video conferencing or web conference $[17,21,22]$. From these evidences, it has shown that collaborative learning has been announced as the successful learning pedagogy. This paper thus implements the concept of collaborative learning into the developed games to promote the better understanding to the content and team work experience to students.

\section{PROPOSED WORK}

This paper proposes the multi-player online game for education to promote the higher learning efficiencies of Thai primary school students having the age between 11-12 years old for three subjects including English language, Mathematics and Science for Life as its structure is shown in Figure 1.

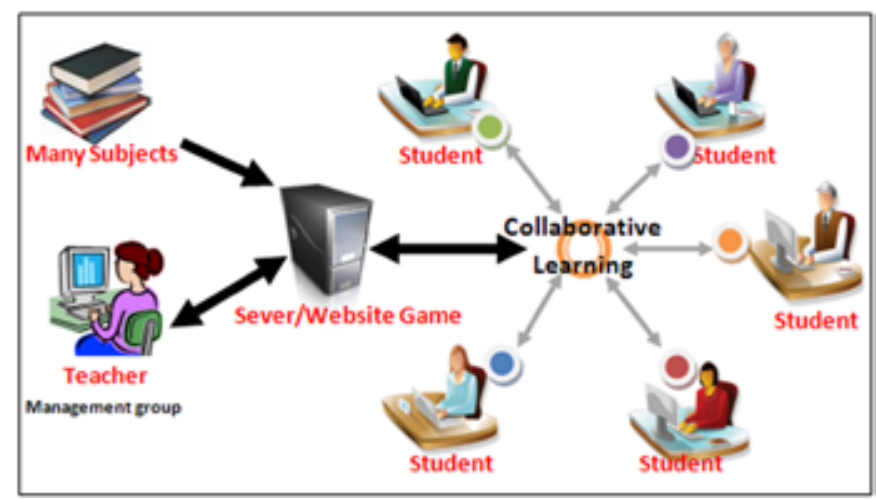

Fig. 1. Multi-player online game architecture

The online game is proposed for the convenience access of students anywhere. As mentioned before, the proposed game also implements the concept of collaborative learning to promote the collaborative atmosphere through team work skills to the students. The students can also learn social skill better through this game because they don't know each other before but they have to work together. The developed game is designed to have the following components.

3.1 Goal: Students are fun, challenged, and excited and at the same time they can learn three subjects simultaneously while playing the game. The English language emphasizes only in the vocabulary. The mathematics aims to practice fast calculation. Finally, the Science for Life aims to explain the scientific phenomenon in daily life. 


\subsection{Game Features:}

3.2.1 Collaborative Learning Module: The chat room is a communication channel for sharing knowledge together and promoting the collaboration atmosphere in the game.

3.2.2 Self Learning Module: The repositories of contents for all three subjects are also provided for students for their individual learning.

3.2.3 Rules: All members of the team have the right to play sequentially in each round by walking through the given pavement as shown in Figure 2. Along the walk, the different questions will be given to the students for collecting the rewards to help them getting the goal. The different types of questions are shown Figure 3.

3.2.4 Challenges: The game is also designed to challenge the students by having the competition module. The team members will have to compete among each other to gain the maximum power so that he/she could gain more power for helping team members to achieve the goal.

3.2.5 Appearance: The game is designed to have a colorful cartoon graphics, animation, and music as shown in Figure 2.

3.2.6 Management Group: There is the management module for the teachers to manage the group members.

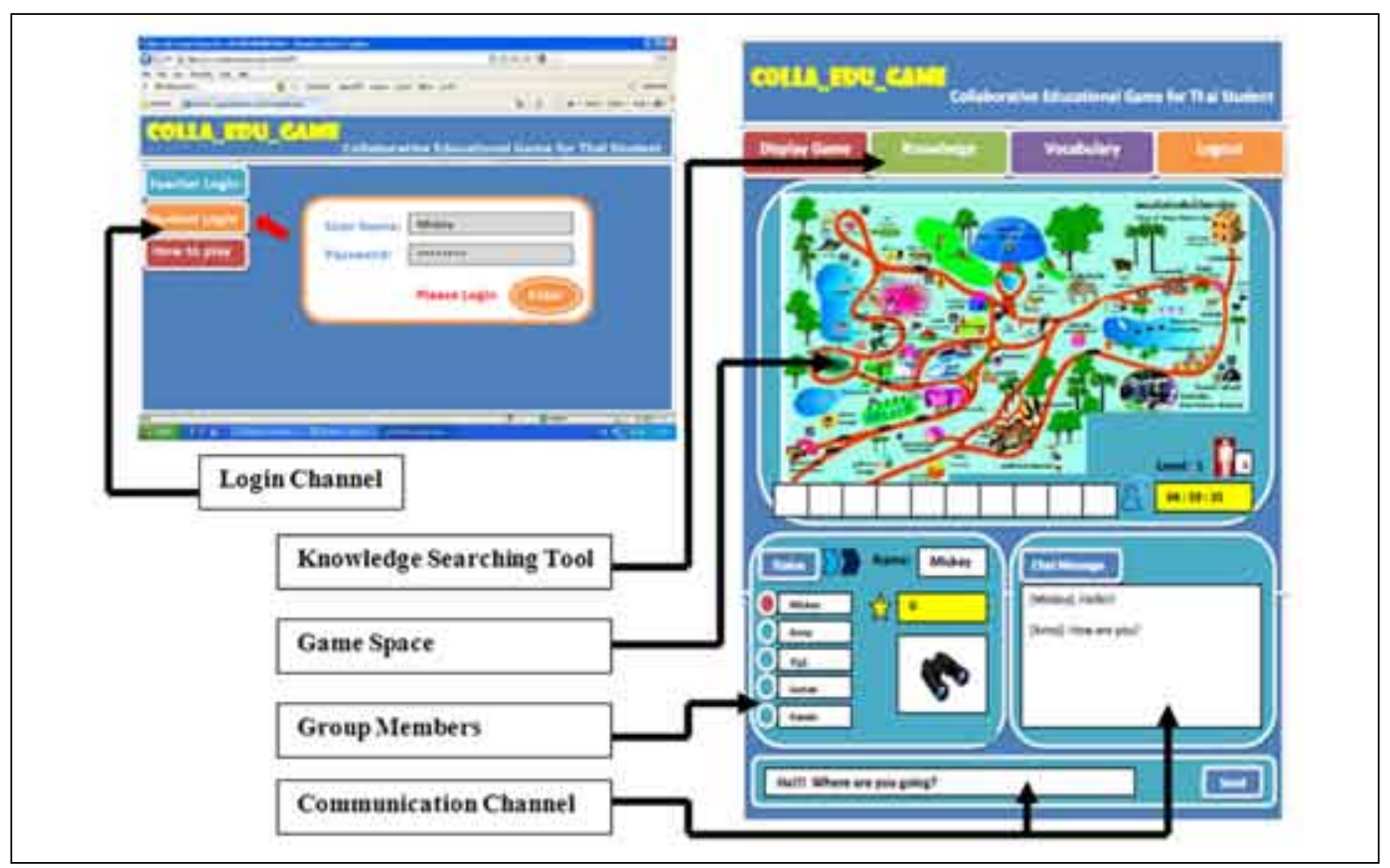

Fig. 2. Game appearance snapshot.
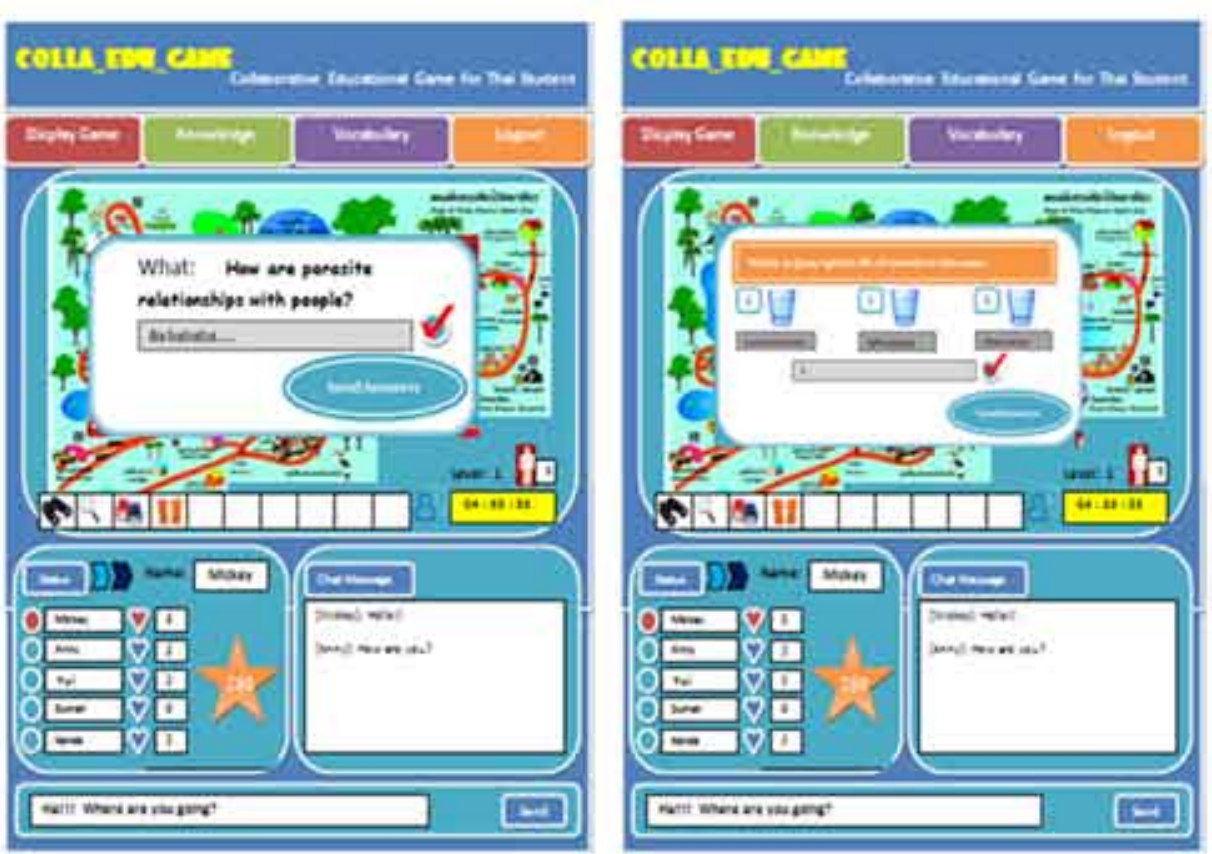

Fig. 3. Questions appearance snapshot 


\section{RESEARCH METHODOLOGY}

There are 5 steps for the methodology of this paper as shown in Figure 4.

(1.) Studying and Analyzing Basic Information

(2.) Designing Game

(3.) Developing Game

\section{1}

\section{(4.) Testing and evaluating}

(5.) Studying Results

Fig. 4. Research Methodology

4.1 Studying and Analyzing Basic Information: This process emphasizes the preparation of basic information for developing the online game such as the infrastructure and the implementation requirements. The content of each subject is also prepared in this step.

4.2 Designing game: This step is about designing all components required for the proposed game as mentioned before in section 3 . The game story is about kidnapping everybody in school and the hostages are kept into the different locations for testing new chemicals on human, but five students are safe. Group members must collaborate among each other to find the places and find the key to turn the door to help hostage within the limited time limit, or until they can destroy the chemical laboratory successfully.

4.3 Developing game: This is the step of implementing the designed game. Macromedia Flash program for creating characters and inserting coast scripts, Adobe Swish Max program is used for creating each scene, Photoshop CS program is used for creating object, and Adobe Audition 1.5 program is used for entering and adjusting music and sound.

4.4 Testing and evaluating: This process is to test the developed game with the target students. The target students are 100 grade six Thai students in Chiang Rai province, Thailand. The students have the same age which is between 11-12 years old. The evaluation is conducted in order to investigate 2 main aspects including to which extent the game can make the students achieve higher learning efficiencies in English language,
Mathematics and Science for Life and to which extent the students satisfy this game. The design of group management is shown in Figure 5, where the team members are chosen randomly from 3 different schools.

\section{EMPIRICAL STUDY \& RESULTS}

As mentioned before, the game is online game, the target students are selected mostly from the schools having good quality of internet connection. The numbers of 100 grade six Thai students, from 3 primary schools in Chiang Rai, Thailand are divided into 2 groups. The first group consists of 25 students. This group plays the developed game individually. The second group consists of 15 groups of students and 5 persons per each. This group plays the developed game collaboratively. The students do not know each other before. Before and after playing the game, all students are asked to have the pre-test and post-test respectively. The scores of the second group are randomly chosen only 25 students from 75 students to compare with the students from the first group. Both tests are multiple choices with 4 alternatives for each subject. The different scores of pre-test and post-test of both groups reveal how collaborative learning can help the students to enhance their learning efficiencies in those 3 subjects. Table 1 shows the comparison of pre-test and post-test scores for both groups of students. The results from Table 1 show that the students from the first group have enhanced their scores with Mean $=7.58$ or $25.27 \%$, while the students in the second group have enhanced their scores with Mean $=10.02$ or $33.40 \%$. Therefore, it can be concluded that the students playing the game collaboratively have higher learning efficiencies than the students playing the game individually.

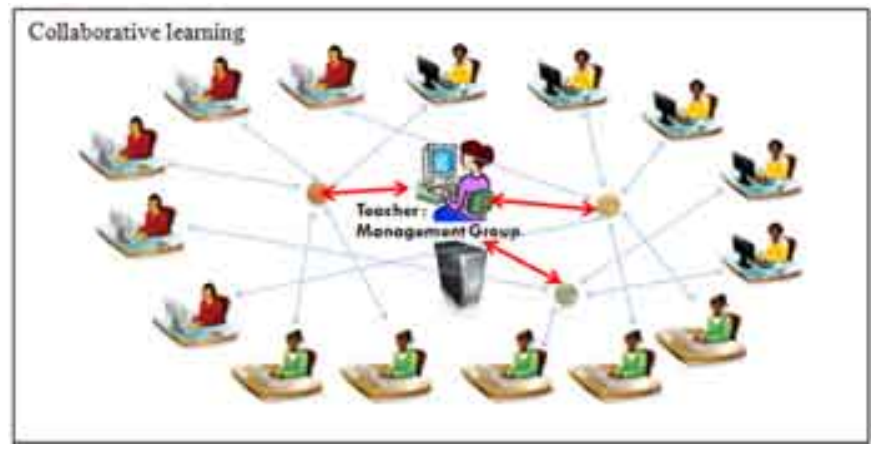

Fig. 5. Group management by the teacher

Table 1. Comparative pre-test and post-test scores of students playing educational game individually and collaboratively

\begin{tabular}{|c|c|c|c|c|}
\hline \multicolumn{2}{|c|}{ Educational Game Type } & N & Mean & Percent \\
\hline \multirow{2}{*}{$\begin{array}{c}\text { Individual } \\
\text { Game }\end{array}$} & Pre-Test & 25 & 15.18 & 50.60 \\
\cline { 2 - 5 } & Prost-Test & 25 & 22.76 & 75.87 \\
\hline \multicolumn{2}{|c|}{ Advancement } & +7.58 & $\mathbf{2 5 . 2 7}$ \\
\hline $\begin{array}{c}\text { Collaborative } \\
\text { Game }\end{array}$ & Pre-Test & 25 & 15.18 & 50.60 \\
\cline { 2 - 5 } & Prost-Test & 25 & 25.20 & 84.00 \\
\hline \multicolumn{2}{|c|}{ Advancement } & $+\mathbf{1 0 . 0 2}$ & $\mathbf{3 3 . 4 0}$ \\
\hline
\end{tabular}


Moreover, the students playing the game collaboratively are also asked about their satisfactions to the game. The questionnaires with 3 different rating scales are used in this process to study how collaborative game satisfies the students. In this paper, the poor level, the fair level and the good level are the scores between 1.00-1.50, 1.51-2.50 and 2.51-3.00 respectively. Table 2 shows how the students playing the game collaboratively satisfy the developed game for different criterion.

Table 2. Satisfaction results of collaborative educational game

\begin{tabular}{|l|c|c|c|}
\hline \multicolumn{1}{|c|}{ Satisfaction Criterion } & Mean & Std dev. & Level \\
\hline 1. Illustration in a colorful game & 2.87 & 0.35 & Good \\
\hline 2. Readable characters & 2.93 & 0.25 & Good \\
\hline 3. Language easy to understand & 2.87 & 0.35 & Good \\
\hline 4. Qualities of sound and music & 2.47 & 0.63 & Fair \\
\hline 5. Interesting and observable story & 2.53 & 0.51 & Good \\
\hline 6. How to play straight forward & 2.97 & 0.81 & Good \\
\hline 7. Suitable play time & 2.57 & 0.63 & Good \\
\hline 8. Fun and challenge & 2.60 & 0.56 & Good \\
\hline 9. Content Learning & 2.87 & 0.35 & Good \\
\hline 10. Satisfaction of each subject & 2.87 & 0.35 & Good \\
\hline 11. Team Collaboration & 2.53 & 0.51 & Good \\
\hline 12. Willing to play again & 2.57 & 0.63 & Good \\
\hline \multicolumn{1}{|c|}{ Summary } & 2.72 & 0.22 & Good \\
\hline
\end{tabular}

From Table 2, it can be concluded that the satisfaction of students to the developed collaborative game are averagely in the Good level. Only the Qualities of sound and music is in the Fair level.

\section{CONCLUSION}

This paper proposes the collaborative education game for Thai high school students to promote the higher learning efficiencies of English language, Mathematics and Science for life. Besides providing the collaborative atmosphere, the proposed game also provides the satisfaction in different criterion to the students. The empirical study is conducted with 100 students from 3 different primary schools in Chiang Rai, Thailand. These students are grouped into 2 groups for playing the game individually and collaboratively. The first group consists of 25 students and the second group consists of 15 groups of students which has 5 members per group. The results show that the students playing the game collaboratively have higher learning efficiencies for those three subjects than the students playing individually. Moreover, the proposed game can satisfy those students averagely in the Good level.

\section{REFERENCES}

[1] Qianping WANG, Wei TAN, and Bo SONG. 2007. Research and Design of Edutainment, 1-4244-1385-0/07/2007 IEEE, pp. 502-505.

[2] Yan Wang, Ming Zhang Zuo and Xinag Yong Li. 2007. Edutainment Technology-A New Starting For Educational Development of China. In Proceeding of 37th ASEE/IEEE Frontiers in Education Conference.

[3] Siew, P.H.2005. Evaluation of an Edutainment Animated Folktales Software to MotivateSocio-Cultural Awareness Among Children. Third 2008 International Conference on Convergence and Hybrid Information Technology, DOI 10.1109/ ICCIT. 2008. 368, pp.315319.

[4] Buckingham, D. and Scanlon, M. 2005. Selling. Learning: Towards a political economy of edutainment media. Media, Culture and Society. 27,1, 2005, pp. 41-58.

[5] Nor Azan Mat Zin and Nur Yuhanis Mohd Nasir. 2007. Edutainment Animated Folk Tales Software toMotivate Socio-Cultural Awareness. Computer ScienceChallenges: Proceedings of 7 th WSEAS InternationalConference on Applied Computer Science. Venice,Italy 310-315. Nov 21-23- 2007.

[6] Suwichai Phunsa and Suwich Tirakoat. 2008. A Case study of Developing game Edutainment: “Addictive Danger”. In Proceedings of the 3rd ACM International Conference on Digital Interactive Media in Entertainment and Arts (DIMEA).

[7] Kowit Rapeepisarn, Kok Wai Wong, Chun Che Fung and Arnold Depickere. 2005. Similarities and differences between "learn through play" and "edutainment". School of Information Technlolgy Murdoch University, Australia, pp. 29-32.

[8] Hiroyuki Mitsuhara, Hiroaki Ogata, Kazuhide Kanenishi, and Yoneo Yano. 2006. Real World Interaction Oriented Edutainment using Ubiquitous Devices. Fourth IEEE International Workshop on Wireless, Mobile and Ubiquitous Technology in Education(ICHIT06), 2006.

[9] Bureau of Education Testing, BET.2008. Result of the assessment basic quality of education at Thai Education in 2008 by the Bureau of Education Testing. Retrieved, September 17, 2009 , from http://bet. obec.go.th/eqa/ index.php? option $=$ com content \&task=view\&id $=85 \&$ Itemid $=145$

[10] National Statistical Office of Thailand, TNSO. 2002. Report elementary of surveys children and youth in Thai Kingdom. Retrieved. October 28, 2009 , from http://web.nso.go.th/ en/ stat_theme_socpop. htm

[11] Bangkok University, BU POLL.(2003), Young people with online gaming today. Retrieved. October 28, 2009 , from http:// research. bu.ac.th/ poll/ result/ poll344.php?pollID=160\&Topic= เาวชนกับเกมออนไลน์ยุคปัขจุบัน \&fileDoc $=$ poll344.pdf

[12] Fotini Paraskeva , Sofia Mysirlaki and Aikaterini Papagianni.2009. Multiplayer online games as educational tools: Facing new challenges in learning. Computer \& Education, 2009, doi: 10.1016/ j.compedu. 2009.09.001

[13] Thanomporn Laohajaratsang and Uraiwan Hangwong. 2006. Integrating Game-Based e-Learning Technology in Classroom Setting. Information Technology Service Center, Chiang Mai University

[14] Kim H. Veltman. 2004. Edutainment, Technotainment and Culture. Civita Annual Report 2003, Florence: Giunti, 2004 , pp. 25

[15] Turkan Karakus and Yavuz Inal, Kursat Cagiltay. 2008. A descriptive study of Turkish high school students'game-playing characteristics and their considerations concerning the effects of games, Computers in Human Behavior 242008 , pp 2520-2529

[16] Serkan Coútua, Serhat Aydınb, and Mehmet Filiz. 2009. Students' conceptions about browser-game-based learning in mathematics education: TTNetvitamin case, Procedia Social and Behavioral Sciences 1-2009, pp 1848-1852

[17] Udom Radtanauamponsopon 2004. Collaborative Learning. Retrieved. September 10, 2009, from http://seashore. buu.ac.th/ udom/ collaborative.htm.

[18] Brigitte Denis, and Sylviane Hubert.2001, Collaborative learning in an educational robotics environment, Computers in Human Behavior17, 2001 , pp. 465-480

[19] Natalia Padilla Zea, José Luís González Sánchez, Francisco L. Gutiérrez, Marcelino J. Cabrera,and P. Paderewski. 2009, Design 
of educational multiplayer videogames: A vision from collaborative learning, Advances in Engineering Software40, 2009 , pp. 1251-1260

[20] Carmen L.Z. Gress a, Allyson F, and Hadwin b. 2009. Advancing educational research on collaboration through the use of gStudycomputer-supported collaborative learning (CSCL) tools: Introduction to special issue. Computers in Human Behavior, 2009

[21] Dodge, B. J. 2000. Thinking visually with WebQuests [Online]. Presentation at the National Educational Computing Conference, Atlanta, GA. Available: http://edWeb.sdsu.edu/Webquest/tv/.

[22] Panagiotes S. Anastasiades, Elena Vitalaki,and Nikos Gertzakis.2008, Collaborative learning activities at a distance via interactive videoconferencing in elementary schools: Parents'attitudes. Computer\& Education50, 2008, pp. 1527-1539

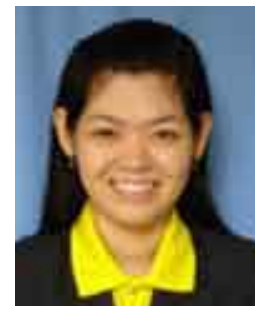

Natticha Gasonpan received her first-class honor for Bachelor's degree of Business Computer from Naresuan University, Phayao, Thailand in 2002. She is currently working towards her Master degree in Strategic Management Information System at Mae Fah Luang University, Chiang Rai, Thailand. Her research interests include educational game, collaborative educational game and computer game integrating the concept of the ancient wisdom game.

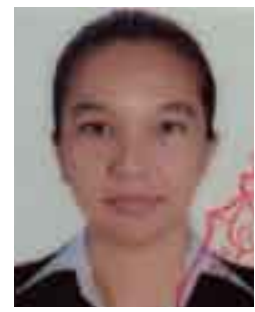

Punnarumol Temdee received her $\mathrm{Ph} . \mathrm{D}$. in Electrical and Computer Engineering from King Mongkut's University of Technology Thonburi, Bangkok, Thailand in 2006. She is currently a lecturer at the school of Information Technology, Mae Fah Luang University, Chiang Rai, Thailand. Her research interests are collaborative learning, computer supported collaborative learning and ubiquitous learning environment. 